\title{
The ACO based Routing Protocols for Mobile Ad Hoc Networks
}

\author{
Joshua Reginald Pullagura, D.Venkata Rao
}

\begin{abstract}
Mobile ad hoc networks are gaining high importance in present days due to many civilian applications apart from regular military applications. Networks usually are designed using fixed infrastructure. Wherever fixed networks are not feasible, ad hoc network serve the purpose. Routing plays an important role in packet transmission, Multicast routing protocols designed for data transfer should consider both bandwidth and energy of the node. Many Ant colony Optimization (ACO) based routing approaches are proposed by researchers. In this paper three popular ACO based routing protocols ANTCHAIN, ANTALG and EMRP-AIPUR are compared using NS2 simulator. The results obtained show that EMRP-AIPUR shows better performance when compared to the other two protocols
\end{abstract}

Keywords: Ant colony optimization, Energy, Routing and Reliability.

\section{I. .INTRODUCTION}

Ad hoc networks can be easily created and deformed without need of any system administration. The nodes should be able to detect other nodes in their range and they should be capable of transferring the packets without any loss. Routing is the process of transmitting Binary information from transmitter or source to receiver. Swarm intelligence (SI) Technology is used in creating routes; specifically Ant Colony Optimization (ACO) [1-6] based routing gained importance. The inspired method that is ACO is adopted from biological like flies, ants, bees etc. A mobile node, as name suggests will move freely in this scenario and thus a network needs to have routing protocols which can adapt dynamically to the changing wireless topology. Usually best route is the one where nodes have high energy and the route should be shortest path with minimum number of hops [3]. However, since there is no fixed infrastructure in a network, each mobile node should operate reliably forwarding packets from one node for other nodes in the network. Nodes are using in this method that is mobile so it would be portable so due to portable the life of battery is less.

Protocols should be able to catch up these fast network changes without poor route convergence and low communication throughput. Sometimes due to malicious nature of the nodes throughput of the network decreases, Vampire attack [8] is one of such case where nodes battery power is drained out by malicious node. Risk free data transfer is one of the main goals of robust routing algorithm. There are many approaches given for improvement of Packet delivery fraction [10].

Revised Manuscript Received on December 15, 2019.

Joshua Reginald Pullagura, Vignans foundation for Science Technology and Research Deemed to be University Guntur, pjreginald@gmail.com

Dr.D.Venkata Rao, QIS College of Engineering and Technology, Ongole
This research paper is divided into four sections, section 2 presents review of ACO based routing algorithms. In Section 3 , we presented details of setup used for evaluation of performance matrices. Section 4 presents the performance matrices and result.

\section{REVIEW OF ACO BASED ROUTING ALGORITHMS}

The routing protocols play an important role in successful packet delivery. Traditionally they are classified into the Table driven proactive, On Demand Reactive and Hybrid protocols. Many ACO based protocols proposed are energy efficient. The following are some of the protocols which shows reliable performance.

\subsection{ANTLAG: Ant colony based Routing Algorithm}

ACO is the one of the oldest routing method among all. Ants (agents) are exchanged between the source and Destination. During the movement of ants, the pheromone tables and data structures are created to record the trip time of the nodes. The movement of packets and Ant's agent through the network changes the routing policy and the paths which are used by future packets in a stochastic manner.

\subsection{ANTCHAIN:}

It is one of the energy efficient data gathering protocol where nodes form an Antchain. The role of Antchain head and Antchain tailor are pre defined for data gathering process and is scheduled by means of a Time Division Multiple Access technique which ensures uniform depletion of energy among sensor nodes. Novel Swarm Intelligence Based Routing Scheme is the one of the method where lightweight ants are used to determine the best path between nodes.

2.3 EMRP-AIPUR: Efficient Multicast Routing Protocol by using Ant with Improved Pheromone Updating Rule

In this mechanism worst ants are identified by using modified TOPSIS method and are removed [1]. Initially, clustering is done to make authentication process easy and the optimal Cluster Head $(\mathrm{CH})$ selection is done with the concern of their security level where the selected cluster head should be trustable and should contain increased energy and bandwidth availability. Here optimal $\mathrm{CH}$ selection is done by using AIPUR.

\section{SIMULATION SET UP}

Network simulator (NS2.35) Simulation tool is used the performance and evolution of these three ACO based routing protocols. Simulation parameters are appended in Table 1

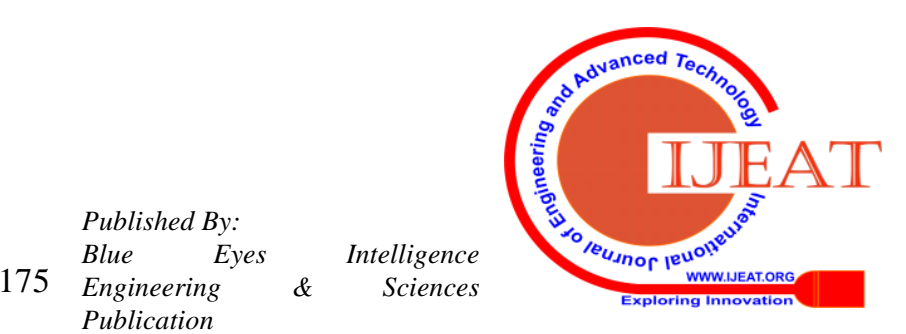


The ACO based Routing Protocols for Mobile Ad Hoc Networks

Table 1

\begin{tabular}{|l|l|}
\hline Parameter & Description \\
\hline Simulator & NS-2 \\
\hline Protocols & $\begin{array}{l}\text { ANTALG, Ant Chain and } \\
\text { EMRP-AIPUR }\end{array}$ \\
\hline Simulation time & $\# \# \# \# \# \# \#$ \\
\hline Data payload & 512 bytes/packet \\
\hline Traffic type & CBR \\
\hline
\end{tabular}

\section{RESULTS AND DISCUSSION}

In this section, EMRP-AIPUR, ANTCHAIN and ANTLALG protocols are compared with the help of simulation. The simulated results are tabulated below.

4.1. Packet delivery fraction: Table 2 shows the Packet delivery fraction, PDF of EMRP-AIPUR increases with increase in simulation time. It shows an average of above 90 PDF because of optimal path selection and availability of Multipath routes.

Table 2

\begin{tabular}{|c|c|c|l|}
\hline $\begin{array}{l}\text { SIMULATION } \\
\text { TIME }\end{array}$ & $\begin{array}{l}\text { ANT } \\
\text { CHAIN }\end{array}$ & ANTALG & $\begin{array}{l}\text { EMRP } \\
\text { AIPUR }\end{array}$ \\
\hline $50 \mathrm{sec}$ & 86 & 89 & 94 \\
\hline $100 \mathrm{sec}$ & 84.55 & 82.811 & 93.7 \\
\hline $150 \mathrm{sec}$ & 85.6 & 78.6 & 93 \\
\hline $200 \mathrm{sec}$ & 86 & 77 & 92 \\
\hline
\end{tabular}

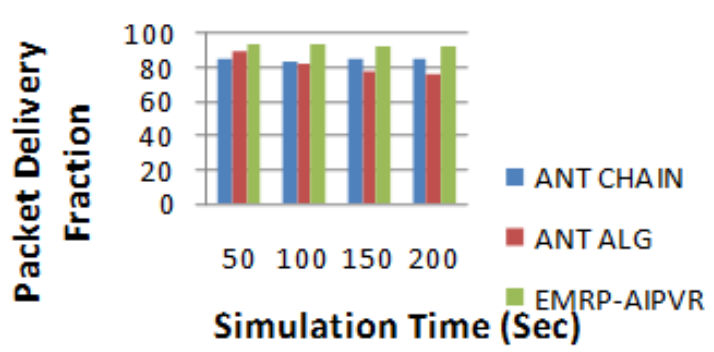

Figure 1

4.2. Throughput (bytes/sec): It gives the no of packets successfully delivered per simulation time. Table 2 gives the Throughput details. When the simulation time is varied from 50 to 200 seconds EMRP-AIPUR gives fair results when compared to other two algorithms because it uses efficient clustering mechanism and $\mathrm{CH}$ selection for every iteration.

Table 3

\begin{tabular}{|r|r|r|r|}
\hline $\begin{array}{l}\text { SIMULATION } \\
\text { TIME }\end{array}$ & $\begin{array}{l}\text { ANT } \\
\text { CHAIN }\end{array}$ & ANTALG & $\begin{array}{l}\text { EMRP } \\
- \\
\text { AIPVR }\end{array}$ \\
\hline 50 & 85983 & 84882 & 91884 \\
\hline 100 & 84528 & 86222 & 91113 \\
\hline 150 & 81914 & 86113 & 91117 \\
\hline
\end{tabular}

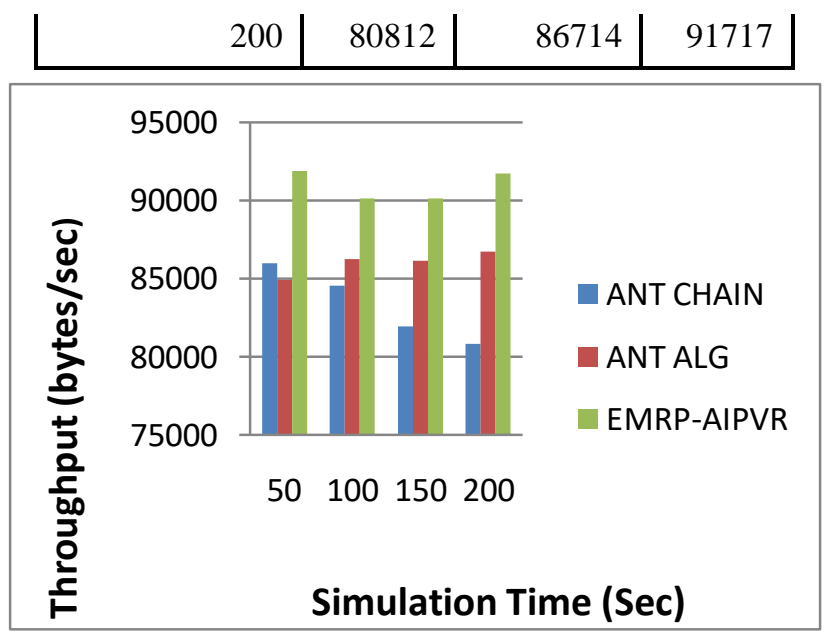

Figure 2

4.3. Percentage routing overhead with varying simulation time:

Routing over head is the factor that needs to be minimized; here the comparative results show EMRP-AIPUR shows better results when compared to other protocols.

Table 4

\begin{tabular}{|r|r|r|c|}
\hline $\begin{array}{l}\text { SIMULATION } \\
\text { TIME }\end{array}$ & ANTCHAIN & ANTALAG & $\begin{array}{l}\text { EMRP- } \\
\text { AIPVR }\end{array}$ \\
\hline 50 & 7.9881 & 6.9012 & 6.4963 \\
\hline 100 & 7.92107 & 7.854 & 6.3741 \\
\hline 150 & 7.1206 & 7.1909 & 6.2791 \\
\hline 200 & 6.9234 & 5.989 & 6.1998 \\
\hline
\end{tabular}

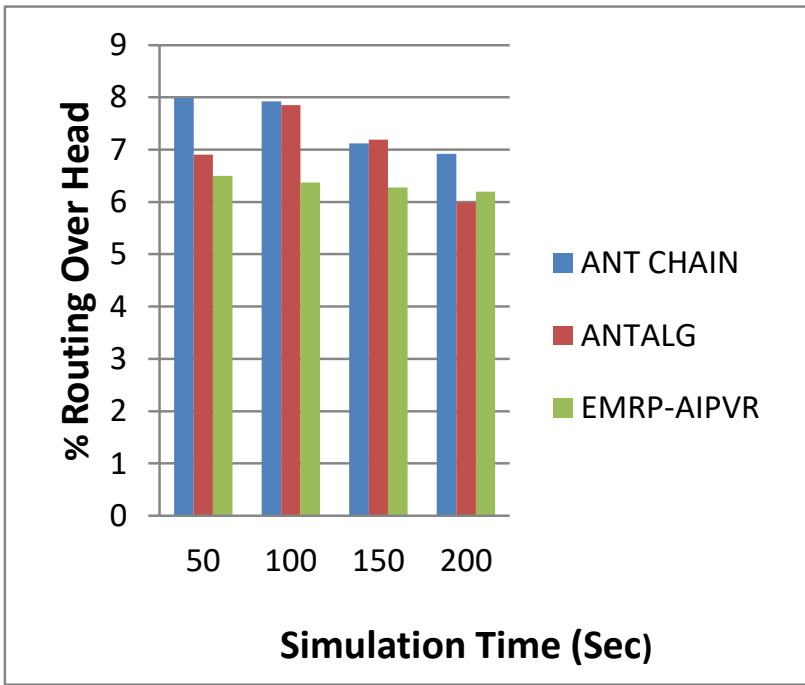

Figure 3

\section{CONCLUSION}

In this Paper simulation results show that EMRP-AIPUR shows better results when compared to other two protocols due to proper cluster head selection and key mechanism it adopted. It guarantees authentic multicast routing with increased security mechanisms.

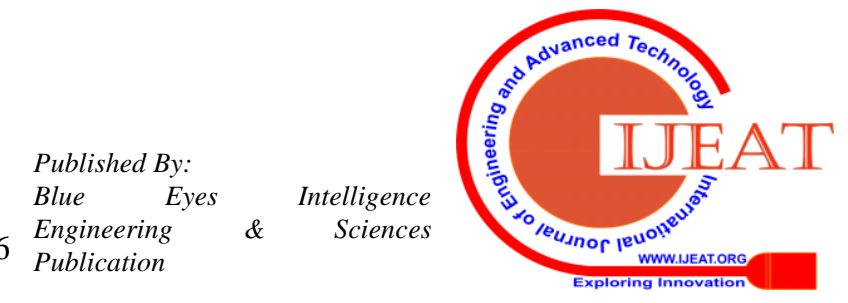




\section{REFERENCES}

1. Joshua Reginald Pullagura and Dr.D.Venkata Rao, “An Efficient Multicast Routing Protocol Based on Ant with Improved Pheromone Updating Rule in Manet" in International journal of Simulations, systems Science and Technology (IJSSST), 2018, DOI 10.5013/IJSSST.a.19.06.19, ISSN: 1473-804x online, 1473-8031 print.

2. Batth KK, Singh R (2017) "Performance Evaluation of Ant Colony Optimization Based Routing Algorithms for Mobile Ad Hoc networks in International journal of Advancements in Technology Vol 8, issue 2:181.

3. Joshua Reginald Pullagura, D.VenkataRao " Simulation based performance evaluation of energy efficient protocols in ad hoc netwo rks", Journal of Advanced Research in Dynamical and Control Systems , Special Issue - 02 / 2017, volume 9,pp 11411149.

4. Sim KM, Sun WH (2003) Ant colony optimization for routing and loadbalancing: survey and new directions. IEEE Transactions on Systems, Man, and Cybernetics-Part A: Systems and Humans 33: 560-572.

5. Nayyar A, Singh R (2016) Ant colony optimization-computational swarm intelligence technique. IEEE Transactions on Systems, Man, and Cybernetics - Part A: Systems and Humans 33: 560-572.

6. Kaur K, Singh R (2016) Swarm intelligence for routing in mobile Ad Hoc networks. Int J Adv Inf Sci Tech 4:

7. Dorigo M, Birattari M, Stutzle T (2006) Ant colony optimization. IEEE computational intelligence magazine 1: 28-39.

8. Pullagura, Joshua Reginald, and Dhulipalla Venkata Rao. "Simulation-Based Comparison of Vampire Attacks on Traditional Manet Routing Protocols." Information and Communication Technology for Sustainable Development. Springer, Singapore, 2018. 501-509.

9. Saha, Seemanti \& Pathak, Sant. (2006). A Novel Swarm Intelligence Based Routing Scheme for Manet using Weighted Pheromone Paths. 1 - 7. 10.1109/MILCOM.2006.302450.

10. J. Wang, T. Mikami, K. Kanamori, E. Kodama, and T. Takada, “An effective approach to improving packet delivery fraction of ad hoc network," in Lecture Notes in Engineering and Computer Science: Proceedings of The International MultiConference of Engineers and Computer Scientists 2011, IMECS 2011, Hong Kong, 2011, pp. $681-686$.

Published By:

Blue Eyes

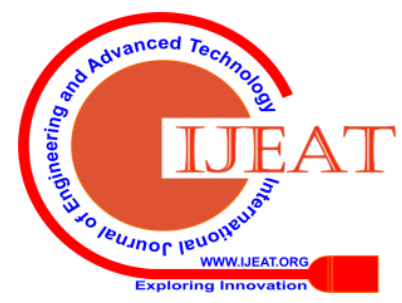

